\title{
Respuesta emocional en adictos a sustancias en tratamiento ambulatorio
}

\section{Emotional responsiveness of substance abusers under outpatient treatment}

\author{
Juan Chicharro*; Ana M. Pérez-García*; \\ PILAR SANJuán ${ }^{\star *}$.
}

\author{
* CAD 4 San Blas. Instituto de Adicciones. Madrid Salud. Ayuntamiento de \\ Madrid. \\ ** Universidad Nacional de Educación a Distancia (UNED). Facultad de \\ Psicología. Departamento de Personalidad, Evaluación y Tratamiento \\ Psicológicos. \\ Enviar correspondencia a: \\ Juan Chicharro Romero \\ CAD IV (San Blas). C/ Alcalá, 527. 28027 Madrid. \\ Email: chicharrorj@madrid.es \\ TIf: 917434771
}

\section{Resumen}

Las emociones predisponen para la acción proporcionando información tanto del ambiente interno como del externo. Hay evidencia de que la respuesta emocional en pacientes drogodependientes es distinta a la de la población no consumidora. El presente trabajo analizó las emociones en drogodependientes en tratamiento ambulatorio $(\mathrm{N}=57)$, siguiendo la teoría de la emoción de Lang, con las dimensiones de valencia, activación y dominancia o control, a través del International Affective Picture System (IAPS), aplicado de forma individual. Se contrastaron sus respuestas con un grupo control de personas no consumidoras $(\mathrm{N}=44)$ de similar edad, variable que afecta a la experiencia emocional. De la misma forma se analizó la influencia del sexo, dadas las posibles diferencias en experiencia emocional entre varones y mujeres.

Los resultados pueden resumirse en los siguientes puntos: (1) Hubo diferencias significativas entre adictos a sustancias y no consumidores en la dimensión de valencia, valorando los consumidores los estímulos emocionales de forma más extrema (los agradables como mejores y los desagradables cómo peores); (2) No hubo diferencias entre ambos grupos en las dimensiones de activación y de dominancia; y (3) Las mujeres se activaban más ante imágenes de tipo aversivo y menos ante las sexuales que los varones, con independencia de que fueran o no consumidoras de sustancias.

Finalmente, se sugiere la necesidad de profundizar en el estudio de las diferencias de sexo, en las imágenes analizadas, así como en la utilidad de las terapias centradas en la emoción para el tratamiento de las drogodependencias.

Palabras clave: Drogodependientes, emoción, International Affective Picture System (IAPS), Lang, tratamiento ambulatorio, diferencias de sexo. recibido: Julio 2011 aceptado: Noviembre 2011

\section{Abstract}

The emotions predispose to action providing information from both internal and external environment. There is evidence indicating that the emotional response in drugdependent patients is different from that of the not consuming population. The present work analyzed the emotions of drugdependent under ambulatory treatment $(\mathrm{N}=57)$, following the Lang's theory of emotion, considering the dimensions of valence, arousal and dominance or control, across the International Affective Picture System (IAPS), individually applied. The results were contrasted with a control group of not consuming persons $(N=44)$ of similar age, since this variable concerns emotional experience. The influence of sex was also analyzed, considering the possible differences between men and women in emotional experience.

The results can be summarized in the following points: (1) There were significant differences between substance abusers and not consumers in the dimension of valence, valuing the consumers the emotional stimuli of the most extreme form (the agreeable ones as better, and the disagreeable ones as worse); (2) there were no differences between both groups in the arousal and dominance dimensions; and (3) women reported more arousal before aversive images, and less before the sexual ones, than males, independently of they were or not substance abusers. Finally, it is suggested the need to deep into the analysis of sex differences and into the images selected, as well as into the usefulness of the emotion centred therapies for the treatment of drugdependency.

Key words: Drugdependent, emotion, International Affective Picture System (IAPS), Lang, outpatient treatment, sex differences. 
$\mathrm{E}$ la actualidad existe bastante acuerdo sobre el papel que las emociones juegan en la predisposición para la acción (Lang, 1980; LeDoux 1996). Las emociones aportan información, tanto de los aspectos internos del individuo como de la situación externa (Damasio, 1994), por lo cual tienen un rol importante en el desarrollo del comportamiento y la toma de decisiones (Verdejo y Bechara, 2009).

Una de las teorias de la emoción que más apoyo ha recibido es el modelo bioinformacional de la emoción de Lang (1980; 1994; 1995) (Lang, Öhman y Vaitl, 1988). Este modelo defiende que las emociones predisponen para la acción y que la respuesta emocional cumple dos funciones fundamentales, una social consistente en la expresión y reconocimiento de los estados de ánimo, y otra motivacional, en función de la respuesta de aproximación o evitación que el individuo muestre ante los estímulos (Lang, 1985).

El modelo propone también que las emociones se estructuran de acuerdo a diferentes dimensiones bipolares. La primera hace referencia a la valencia afectiva, y expresa el agrado o rechazo que produce un estímulo, es decir, si éste contribuye a la homeostasis o si por el contrario amenaza con desequilibrarla. La valencia depende de los dos sistemas motivacionales, es decir, el apetitivo y el aversivo, en función de que se de una respuesta de aproximación o evitación respectivamente. La segunda dimensión es el arousal o activación, que se refiere a la intensidad con la que se responde ya sea para aproximarse o evitar. La tercera dimensión se refiere al control o dominancia, e indica el grado de control sobre los diferentes estímulos que los sujetos perciben cuando están expuestos a los mismos.

En paralelo al desarrollo de la teoría, Lang y colaboradores también diseñaron en el Center for Study of Emotion and Attention (CSEA) de Florida, un sistema para el estudio de las emociones, conocido como International Affective Picture System (IAPS) (Lang, Bradley y Cuthbert, 1999). Este método consiste en una serie de estímulos emocionales en forma de imágenes fotográficas, que en la actualidad Ilegan hasta, aproximadamente, unas 1200 y que cubren un amplio rango de situaciones de la vida (sexo, deportes, violencia, animales, paisajes, desastres naturales, etc.). Estos estímulos son fácilmente presentables a la hora de realizar estudios y permiten controlar tanto el tiempo de exposición como el momento y lugar en el que ésta se hace. A partir de la evaluación que los individuos hacen de estas imágenes en cada una de las dimensiones emocionales, se pueden obtener puntuaciones que han permitido el estudio de las emociones de manera cuantitativa, así como la validación del instrumento. Dado que en la actualidad está considerado el sistema más fiable, y es el más empleado para el estudio de las emociones (Lang et al. 1999), se ha adaptado a distintas poblaciones, entre las que se encuentra la española (Moltó, Montañés, Poy y Segarra, 1999; Vila, Sánchez y Ramírez, 2001).

Tanto en los estudios realizados por el grupo de Lang (Lang et al., 1988; 1999), como en los realizados para la validación del instrumento en población española (Moltó et al., 1999; Vila et al., 2001), se ha encontrado que las imágenes que en la dimensión de valencia son evaluadas más bajo (que serían las aversivas) y más alto (o agradables), son las que también se valoran más alto en la dimensión de activación. En realidad, las imágenes aversivas se puntúan algo más alto que las agradables en esta dimensión, lo que implica que la respuesta de escape que produce un estímulo aversivo es más fuerte que la respuesta de acercamiento que produce un estímulo placentero. Por otra parte, también se ha encontrado que los estímulos que en la dimensión de valencia se evaluaban con puntuaciones intermedias (que serian los neutros) eran los que obtenian puntuaciones más bajas en la dimensión de activación. Si se construye un eje de coordenadas, con las puntuaciones obtenidas en cada imagen o ítem, en las dimensiones de valencia (en el eje de ordenadas) y activación (en el eje de abcisas), la figura que se obtiene es similar a un boomerang. En los extremos de dicho boomerang, se situarían los estímulos que activan más, que como se ha dicho, son los que tienen baja y alta valencia, o lo que es lo mismo, los estímulos aversivos y placenteros respectivamente. Dado que los estímulos con valencia negativa activan algo más que los estímulos emocionales con valencia positiva, se forma la figura del boomerang, con un brazo ligeramente más largo que el otro. En la parte central del boomerang se colocarian los estímulos calificados como neutros, que son los que menos activan.

Dentro de este marco conceptual, el objetivo principal del presente trabajo fue estudiar la respuesta emocional en un grupo de personas drogodependientes. Por una parte, y tal como se ha comentado, la experiencia emocional tiene influencia en la conducta, por lo cual el estudio de las emociones adquiere especial relevancia si se pretende entender la conducta consumidora (Verdejo y Bechara, 2009). Por otra parte, estudios previos con este colectivo han mostrado que presentan una respuesta emocional peculiar (Gerra et al., 2003; Goldstein y Volkow, 2002; Verdejo y Bechara, 2009). Sin embargo, en este área de estudio, existen algunos factores, como el sexo o la edad, que sabemos tienen efecto en el procesamiento emocional (Grühn y Scheibe, 2008; Moltó et al. 1999; Vila et al. 2001), pero que no han sido tenidos en cuenta a la hora de estudiar a este grupo, aunque podrían estar contribuyendo a esa respuesta diferencial.

En cuanto a la respuesta emocional diferencial del colectivo de drogodependientes, estudios realizados en población española con muestras de pacientes drogodependientes en tratamiento, a los que se exponía a imágenes del IAPS, mostraron que éstos informaban una experiencia emocional diferente a la presentada por el grupo de la adaptación española, pues mostraban menor activación y mayor control ante la exposición a imágenes agradables, mientras que se activaban más ante las desagradables (Aguilar et al., 2005a, 2005b, 2008a, 2008b).

Respecto a la influencia del género, algunos estudios han encontrado que hombres y mujeres difieren en la respuesta emocional. En concreto, los distintos estudios de validación del IAPS realizados con población no consumidora mostraron que las mujeres se activaban más ante imágenes de tipo aversivo (Moltó et al. 1999; Vila et al. 2001). Por ello, con el objetivo de explorar si también se mostraban estas diferencias a pesar del consumo de drogas, se optó por estudiar también una muestra de mujeres drogodependientes (Del Pozo, 2005). 
En relación a la edad, se ha encontrado que tiene cierta influencia en la respuesta emocional. Así, algunos estudios han mostrado que las personas con más edad con respecto a las más jóvenes, valoran las imágenes negativas más bajo en la dimensión de valencia y más alto en la de activación, mientras que las imágenes positivas eran valoradas más alto en la dimensión de valencia y más bajo en la de activación (Grühn y Scheibe, 2008). A pesar de que la edad es una variable que tiene cierta incidencia en la respuesta emocional, los estudios realizados con drogodependientes han empleado normalmente como grupo control de comparación el utilizado para la validación del IAPS, que tenía una edad media de 21 años, aunque el grupo de drogodependientes tuviera una edad media significativamente más elevada. Para controlar el efecto de la edad, en este estudio se compara al grupo de consumidores con otro control de edad equiparable.

Además del estudio de una muestra de mujeres drogodependientes y del control del efecto de la edad, nuestro estudio también tiene algunas diferencias con respecto a los realizados previamente. Por un lado, los participantes consumidores del presente estudio estaban en tratamiento en régimen ambulatorio, a diferencia de otros estudios en los que se encontraban ingresados en una comunidad terapéutica (Aguilar et al., $2005 a, 2005 b, 2008 a, 2008 b)$. Este hecho implica que probablemente los participantes de nuestro estudio tendrian un grado de adicción y deterioro cognitivo menor.

Por otra parte también se han incluido algunas modificaciones en el procedimiento de aplicación. En las validaciones del IAPS la exposición a las imágenes se hizo en grupos de entre 8 y 25 personas, proyectando en una pantalla los estímulos visuales (Moltó et al., 1999). En algunos estudios, aunque se han administrado los estímulos emocionales en grupos más reducidos, las imágenes se han presentado en un cuadernillo. En otros estudios, que han empleado neuroimagen o medidas fisiológicas, aunque se supone que la presentación de imágenes se hace de forma individual por las características de los aparatos empleados, la realidad es que no se especifica en los estudios. En el presente trabajo, por el contrario, se aplicó el IAPS de forma individual presentando las imágenes a través de una pantalla de ordenador, evitando así las posibles interferencias de la respuesta en grupo y mejorando de esta forma la fiabilidad de los resultados.

A modo de resumen se podría decir que con el presente estudio se pretendia estudiar la respuesta emocional de un grupo de drogodependientes en tratamiento en régimen ambulatorio, teniendo en cuenta las posibles diferencias entre varones y mujeres, la comparación con un grupo control con edad equiparada y utilizando un procedimiento de exposición individual de las imágenes emocionales.

De acuerdo con los diferentes resultados presentados previamente, esperábamos que el grupo de drogodependientes, con respecto al grupo control de no consumidores, puntuaran menos en la dimensión de activación y más en la de control ante las imágenes agradables o positivas, mientras que se activarían más ante las desagradables. Adicionalmente, queríamos explorar si estos patrones de respuesta se mantenían cuando se comparaban con un grupo de no consumidores de edad similar. En relación al estudio de las dife- rencias en función del género, esperábamos que las mujeres, con respecto a los hombres, evaluaran más alto las imágenes aversivas en la dimensión de activación.

\section{Método}

\section{Participantes}

La muestra estuvo formada por dos grupos cuyas caracteristicas quedan recogidas en la Tabla 1. El primero incluía personas que solicitaban tratamiento a causa de trastornos adictivos en un Centro de Atención a Drogodependientes del Ayuntamiento de Madrid ( $N=57)$, y que cumplian los criterios de abuso o dependencia de sustancias según el DSMIV (American Psychiatric Association, 2002); en tanto que el segundo grupo, estaba formado por personas que nunca habían sido atendidas por consumo de drogas $(\mathrm{N}=44)$. En ambos casos, todas las personas que colaboraron en el estudio lo hicieron de forma voluntaria, recibieron información sobre el objetivo del estudio y firmaron una hoja de consentimiento informado. Los datos fueron recogidos en los meses de marzo, abril y mayo de 2009.

El $53,5 \%$ de la muestra total $(N=101)$ estuvo constituida por hombres, y el $46,5 \%$ por mujeres. Dentro del grupo de consumidores de sustancias el $71,9 \%$ eran hombres y el resto mujeres, siendo una distribución similar a la de personas que solicitan tratamiento por conductas adictivas. En la población no consumidora las mujeres representaban el 70,5\%. A nivel académico, el 93\% de la población no consumidora tenían estudios universitarios o de formación profesional, mientras que en los consumidores el porcentaje era del 25\%. Las sustancias por las que solicitaban tratamiento eran: alcohol, cocaína, heroína (se incluyeron pacientes en programa de metadona), cánnabis y otras adicciones.

Tabla 1. Descripción de los dos grupos de la muestra.

\begin{tabular}{|c|c|c|}
\hline & Adictos & Control \\
\hline \multicolumn{3}{|l|}{ Sexo } \\
\hline Varones & $41(71,92 \%)$ & $13(29,55 \%)$ \\
\hline Mujeres & $16(28,07 \%)$ & $31(70,45 \%)$ \\
\hline \multicolumn{3}{|l|}{ Nivel de estudios } \\
\hline Sin estudios & $1(1,75 \%)$ & 0 \\
\hline Bachiller elemental & $27(47,37 \%)$ & $3(6,82 \%)$ \\
\hline Bachiller superior & $15(26,32 \%)$ & 0 \\
\hline Formación profesional & $7(12,28 \%)$ & $8(18,18 \%)$ \\
\hline Estudios universitarios & $7(12,28 \%)$ & $33(75 \%)$ \\
\hline \multicolumn{3}{|l|}{ Edad } \\
\hline Media & 34,61 & 39,86 \\
\hline D.t. & 8,6 & 12,98 \\
\hline Rango & $20-52$ & $18-73$ \\
\hline \multicolumn{3}{|l|}{ Sustancia } \\
\hline Alcohol & $14(24,56 \%)$ & \\
\hline Cocaina & $24(42,11 \%)$ & \\
\hline Heroina & $14(24,56 \%)$ & \\
\hline Cannabis & $3(5,26 \%)$ & \\
\hline Otros & $2(3,51 \%)$ & \\
\hline
\end{tabular}




\section{Medidas y procedimiento}

Al principio de cada sesión se informó a los participantes de las caracteristicas de la tarea que iban a realizar y se solicitó su consentimiento para participar en el estudio y utilizar sus datos con fines investigadores. Todas las sesiones se realizaron entre las 13:00 y las 18:00 horas en la misma habitación.

Los sujetos fueron entrenados en la tarea mediante una imagen de prueba y, cuando se evidenció una suficiente comprensión del procedimiento, se expusieron las imágenes en ordenador mediante una presentación en PowerPoint, estando el participante a una distancia aproximada del monitor de unos $90 \mathrm{~cm}$.

Primero aparecía durante 5 segundos la diapositiva en la que se indicaba "Prepárese para evaluar la siguiente diapositiva en la línea X". Seguidamente, durante 6 segundos se mostraba la diapositiva cuya imagen debía ser evaluada. Por último se proyectaba la diapositiva de evaluación indicando "Por favor, evalúe la imagen en las tres dimensiones" durante 15 segundos. Las imágenes se mostraron con un tamaño de $34 \times 27 \mathrm{~cm}$.

La valoración de las imágenes se realizó con el Maniquí de Autoevaluación (SAM -Self Assessment Manikin; Lang,
1980). Este instrumento, de carácter pictográfico, proporciona una medida para cada imagen en cada una de las tres dimensiones a través de cinco figuras humanoides que varian en intensidad (tamaño, forma, expresión) con una escala de 9 puntos (ver Figura 1)

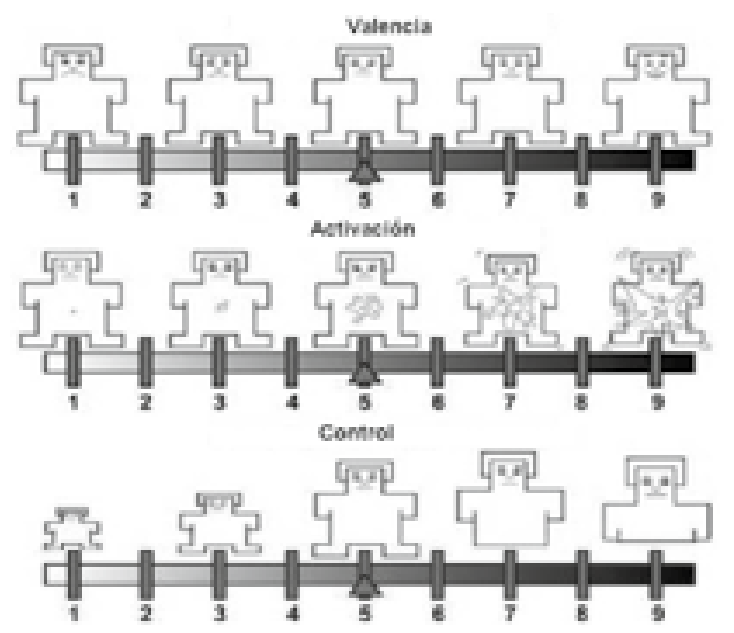

Figura 1. Maniquí de Autoevaluación (SAM -Self Assessment Manikin; Lang, 1980)

Tabla 2. Orden de presentación de las imágenes seleccionadas.

\begin{tabular}{|c|c|c|c|c|c|c|c|}
\hline $\mathrm{N}^{\circ}$ de presentación & Descripción & Conjunto & $\mathrm{N}^{\circ}$ & $N^{\circ}$ de presentación & Descripción & Conjunto & $\mathrm{N}^{\circ}$ \\
\hline Ejemplo & Niños & 14 & 2224 & & & & \\
\hline 1 & León & 14 & 1731 & 26 & Cuchillo & 13 & 6555 \\
\hline 2 & Fumador & 13 & 2715 & 27 & HIV positivo & 7 & 9006 \\
\hline 3 & Zapatos & 13 & 7038 & 28 & Hombre atractivo & 13 & 4537 \\
\hline 4 & Mujer erótica & 14 & 4141 & 29 & Cabeza de ciervo & 14 & 2981 \\
\hline 5 & Cazador/oso & 14 & 2688 & 30 & Mujeres & 14 & 2595 \\
\hline 6 & Hombre en bar & 3 & 2600 & 31 & Muchachos & 13 & 2388 \\
\hline 7 & Pájaros & 13 & 1419 & 32 & Drogadicto & 4 & 2710 \\
\hline 8 & Tigre & 14 & 1726 & 33 & Sexo & 5 & 4810 \\
\hline 9 & Enfermo de SIDA & 3 & 3230 & 34 & Niño con moscas & 14 & 2095 \\
\hline 10 & Hombre erótico & 14 & 4538 & 35 & Hombre Neutro & 13 & 2493 \\
\hline 11 & Edificio quemado & 14 & 9471 & 36 & Pareja romántica & 13 & 4623 \\
\hline 12 & Mujer & 14 & 2025 & 37 & Hombre erótico & 14 & 4503 \\
\hline 13 & Hombre en piscina & 13 & 2055 & 38 & Contaminación & 14 & 9342 \\
\hline 14 & Tiburón & 13 & 1932 & 39 & Hombre Neutro & 13 & 2499 \\
\hline 15 & Alcohólico & 6 & 2750 & 40 & Mujer erótica & 13 & 4142 \\
\hline 16 & Pareja erótica & 13 & 4676 & 41 & Guerra & 13 & 2683 \\
\hline 17 & Mujer & 14 & 2399 & 42 & Ratero & 13 & 2745 \\
\hline 18 & Tren & 13 & 7039 & 43 & Pareja & 14 & 4625 \\
\hline 19 & Bebé & 14 & 2071 & 44 & Sexo & 6 & 4800 \\
\hline 20 & Perro & 13 & 1525 & 45 & Policía & 13 & 2694 \\
\hline 21 & HIV positivo & 8 & 9005 & 46 & Columna & 13 & 7161 \\
\hline 22 & Mujer erótica & 13 & 4255 & 47 & Muchachos & 13 & 2387 \\
\hline 23 & Muchachos & 14 & 2278 & 48 & Tigre muerto & 13 & 6415 \\
\hline 24 & Chica neutra & 13 & 2441 & 49 & Hombre & 14 & 2357 \\
\hline 25 & Flores & 13 & 5811 & 50 & Familia & 13 & 2299 \\
\hline
\end{tabular}


Para llevar a cabo este estudio se seleccionaron 50 imágenes del IAPS, en función de sus valores en las dimensiones de valencia y activación. Respecto a la primera, se seleccionaron imágenes con valores altos, bajos e intermedios intentando replicar la figura del boomerang que aparece en los estudios de validación del IAPS. De la segunda se eligieron aquellas que presentaban valores altos, con el fin de corroborar datos previos que informaban de menor activación en los consumidores que en la población normal (Aguilar et al., 2008a y b). Finalmente, el grupo de estímulos visuales con temática sexual se seleccionó por su relevancia motivacional, como han puesto de manifiesto estudios previos con drogodependientes (Aguilar et al., 2008b). El orden de presentación de las imágenes se dispuso de forma aleatoria. En la Tabla 2 se muestra la secuencia y la descripción de las imágenes, el conjunto al que pertenecen y su numeración en el IAPS.

\section{Análisis estadísticos}

En primer lugar, se realizó un análisis factorial en cada una de las dimensiones emocionales para estudiar la estructura subyacente a la batería de imágenes administrada, comprobando la adecuación de su utilización a través de las pruebas de Kaiser-Meyer-Olkin y de Barlett. En segundo lugar, con los factores obtenidos, se realizaron MANOVAs para analizar los efectos principales del sexo, del grupo o población (adictos y control) y del tipo de imágenes utilizadas, así como las interacciones entre dichas variables, para cada dimensión emocional (valencia, activación y control o dominancia), calculando el tamaño de los efectos significativos encontrados (valor de eta). Cuando el efecto principal de la variable tipo de imagen fue significativo, se realizaron los correspondientes contrastes post-hoc entre los tres niveles considerados en la misma.

\section{Resultados}

En la Figura 2 se recoge la distribución en el espacio bidimensional (activación y valencia) de las 50 imágenes seleccionadas para los grupos de consumidores y no consumidores, observándose en ambos la forma de boomerang. Puede indicarse de forma descriptiva que los consumidores parecen irse hacia valores más extremos en valencia, quedando los valores del grupo control contenidos en la representación de los valores del grupo de consumidores.

Una vez comprobada la similitud de la distribución con la informada en la valoración española del IAPS (Moltó et al., 1999; Vila et al., 2001), se pasó a la agrupación de las imágenes en un número más manejable.

Las pruebas realizadas de Kaiser-Meyer-Olkin (Valencia: 0,73; Activación: 0,63; Control: 0,78) y de Bartlett (Valencia: $\chi_{(1225)}^{2}=3210,5 ; p<0,001 ;$ Activación: $\chi_{(1225)}^{2}=$ 2999,$59 ; p<0,001$; Control: $\left.\chi_{(1225)}^{2}=3652,02 ; p<0,001\right)$ confirmaron que la utilización del análisis factorial era un procedimiento estadístico adecuado para agrupar las

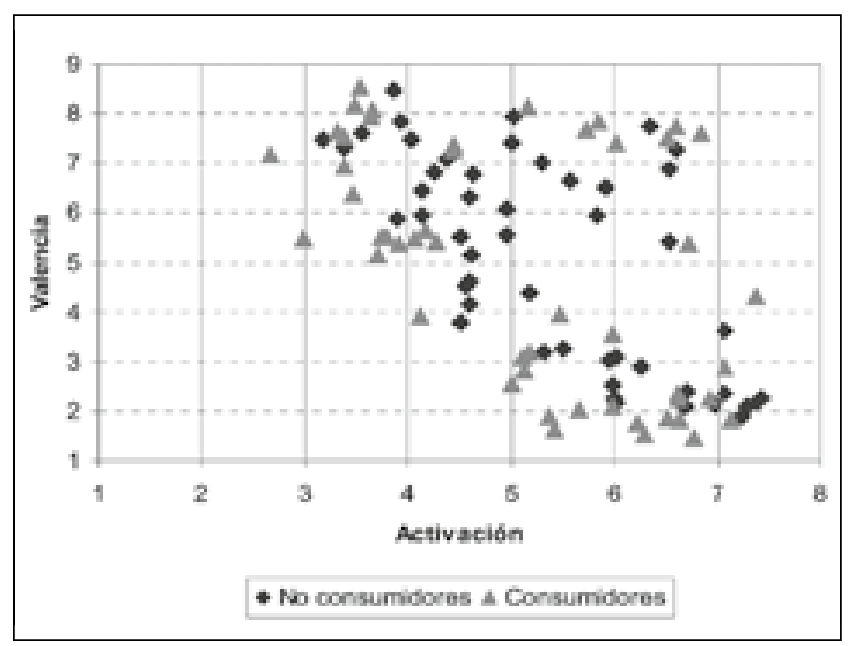

Figura 2. Eje formado por las dimensiones valencia y activación de las imágenes seleccionadas en ambas muestras de consumidores y no consumidores

imágenes en esta muestra en cada una de las dimensiones afectivas. En los análisis se aplicó el método de componentes principales y la rotación Varimax. En función de los datos obtenidos se definieron tres escalas, correspondientes a los tres factores con valores propios mayores de 1 . Estas escalas estaban formadas por tres tipos de estímulos visuales. (1) Sexuales: Escala de imágenes de sexo con alta puntuación en la dimensión valencia compuesta por las imágenes $4,12,22,33,40$ y 44 , con un $8,41 \%$ de la varianza en el componente valencia. (2) Ataques de animales: Escala de imágenes de ataques de animales con alta puntuación en la dimensión de activación compuesta por las imágenes 8,14 y 20 , con un $17,6 \%$ de la varianza en el componente activación. Y (3) Aversivas: Escala de imágenes con baja puntuación en la dimensión valencia compuesta por las imágenes $9,23,32$ y 38, con un 4,64\% de la varianza en el componente control. Se calculó la fiabilidad (alfa de Cronbach) en las tres dimensiones afectivas para cada una de las escalas (ver Tabla 3 ) obteniéndose coeficientes entre 0,64 y 0,87 , que reflejan valores estadísticamente adecuados.

Tabla 3. Fiabilidad de las escalas de imágenes (alfa de Cronbach)

\begin{tabular}{llll}
\hline Escalas IAPS & Valencia & Activación & Control \\
\hline Sexuales & 0,81 & 0,79 & 0,87 \\
Ataques de animales & 0,64 & 0,76 & 0,77 \\
Aversivas & 0,81 & 0,71 & 0,77 \\
\hline
\end{tabular}

Posteriormente, se aplicó el análisis de varianza mixto, siendo los dos primeros factores manipulados entre-sujetos (grupo y género) con dos niveles cada uno (adictos y controles, varones y mujeres, respectivamente), y el tercer factor manipulado intra-sujeto (tipo de imagen), con tres niveles (imágenes sexuales, de ataques de animales y aversivas) para cada una de las dimensiones afectivas (ver Tabla 4 y Figuras 3 у 4$)$. 
Tabla 4. Medias (desviaciones típicas entre paréntesis) en las tres dimensiones de los tres tipos de imágenes para cada grupo y para la muestra total.

\begin{tabular}{|c|c|c|c|c|}
\hline & Imágenes & Control $(\mathrm{N}=44)$ & Consumidores $(\mathrm{N}=57)$ & Total $(\mathrm{N}=101)$ \\
\hline \multicolumn{5}{|l|}{ Valencia } \\
\hline & Sexo & $6,81_{b}(1,22)$ & $7,6_{b}(1,22)$ & $7,25_{\mathrm{a}}(1,27)$ \\
\hline & Ataque de animales & $3,76(1,36)$ & $4,2(1,2)$ & $4_{a}(1,74)$ \\
\hline & Aversivas & $2,4_{c}(1,45)$ & $1,74_{\mathrm{c}}(1,39)$ & $2_{a}(1,45)$ \\
\hline \multicolumn{5}{|c|}{ Activación } \\
\hline & Sexo & $5,86(1,22)$ & $6(1,75)$ & $5,9(1,53)$ \\
\hline & Ataque de animales & $7(1,33)$ & $7(1,8)$ & $7(1,6)$ \\
\hline & Aversivas & $6,42(1,14)$ & $6,1(1,9)$ & $6,24(1,6)$ \\
\hline \multicolumn{5}{|l|}{ Control } \\
\hline & Sexo & $5,7(1,5)$ & $5,6(2,06)$ & $5,63_{\mathrm{d}, \mathrm{e}}(1,83)$ \\
\hline & Ataque de animales & $4,06(2,09)$ & $4,43(2,41)$ & $4,27_{d}(2,27)$ \\
\hline & Aversivas & $4,19(1,76)$ & $4,14(2,23)$ & $4,16_{\mathrm{e}}(2,03)$ \\
\hline
\end{tabular}

Nota: subindices iguales indican diferencias significativas entre las correspondientes medias.

Para la dimensión de valencia se obtuvo un efecto principal significativo del factor tipo de imagen $\left[F_{(2,194)}=235,169\right.$; $p<0,001 ; \eta=0,841]$. Análisis posteriores revelaron que los contrastes entre los tres niveles eran todos estadisticamente significativos $(p<0,001)$ obteniendo mayor puntuación las imágenes de sexo que las de ataques de animales $\left[F_{(1,100)}=188,16 ; \eta=0,808\right]$ y las aversivas $\left[F_{(1,100)}=477,46\right.$; $\eta=0,909]$, y las de ataques de animales que las aversivas $\left[F_{(1,100)}=105,38 ; \eta=0,716\right]$. Es decir, las imágenes sexuales fueron calificadas como más atractivas, en el centro se situaban las de ataques de animales, y las más desagradables o peor valoradas fueron las aversivas.

En el análisis de esta dimensión también se obtuvo una interacción significativa entre los factores grupo (drogodependientes y control) y tipo de imagen $\left[F_{(2,194)}=4,38 ; p<0,04\right.$; $\eta=0,207]$. Análisis más pormenorizados mostraron que los drogodependientes valoraron más positivamente que el grupo control, las imágenes de sexo (puntuación de valencia más alta) $\left[F_{(1,100)}=10,29 ; p<0,002 ; \eta=0,307\right]$ y más negativamente las imágenes aversivas (puntuación de valencia más baja) $\left[F_{(1,100)}=5,33 ; p<0,02 ; \eta=0,226\right]$ (ver Figura 3 ).

\section{Yalensia}

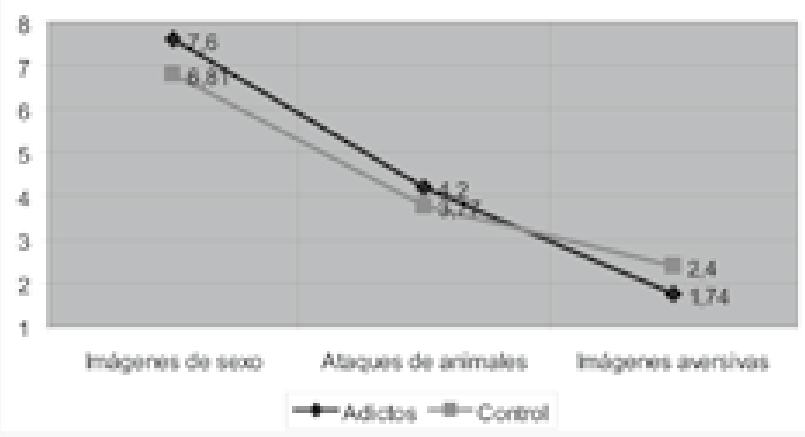

Figura 3. Interacción grupo (drogodependientes y control) $x$ tipo de imagen (sexuales, animales y aversivas) en la dimensión de valencia.
Para la dimensión de activación se obtuvo una interacción significativa entre sexo y tipo de imagen $\left[F_{(2,194)}=14,36\right.$; $p<0,001 ; \eta=0,359]$, siendo los hombres los que más se activaban ante imágenes sexuales $\left[F_{(1,100)}=18,06 ; p<0,001 ; \eta=\right.$ $0,392]$, y las mujeres las que tendían a responder con más intensidad ante imágenes aversivas $\left[F_{(1,100)}=3,31 ; p<0,07 ; \eta=\right.$ 0,179] (ver Figura 4).

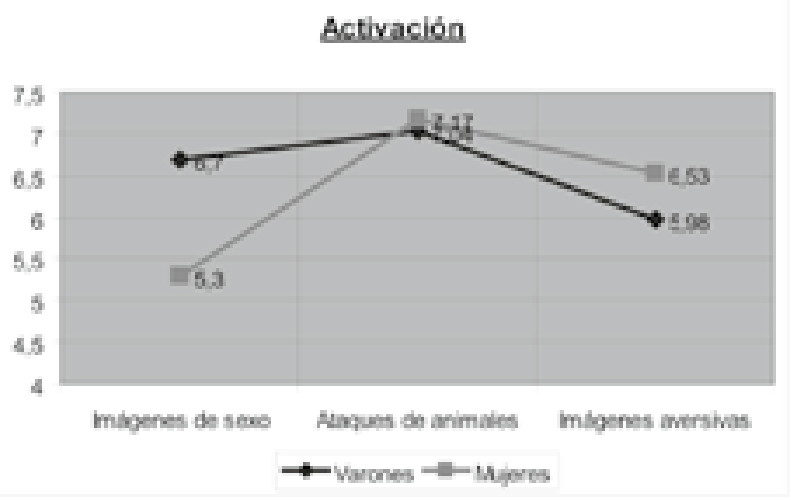

Figura 4. Interacción sexo (varones y mujeres) x tipo de imagen (sexuales, animales y aversivas) en la dimensión de activación

Finalmente, en la dimensión de control sólo se encontró un efecto principal para los diferentes tipos de estímulos $\left[F_{(2,194)}=17,82 ; p<0,001 ; \eta=0,394\right]$, siendo más altas las puntuaciones de control en las imágenes sexuales que en las de animales $\left[F_{(1,100)}=34,98 ; p<0,001 ; \eta=0,509\right]$ y aversivas $\left[F_{(1,100)}=1035,88 ; p<0,0001 ; \eta=0,955\right]$. De esta forma, los estímulos considerados como más agradables, con puntuación en la dimensión de valencia más alta, fueron los que producian una mayor sensación de control; mientras que los estímulos desagradables, con puntuación de valencia más baja, eran los que provocaban una respuesta más estresante o de menor dominio o control. 


\section{Discusión}

El objetivo de este estudio fue analizar la experiencia emocional en una muestra de drogodependientes y compararla con un grupo de no consumidores de edad similar. Los resultados obtenidos no corroboraron las hipótesis planteadas en cuanto a las diferencias en experiencia emocional entre adictos y no consumidores en las dimensiones de activación y control, al no encontrarse diferencias significativas entre ambos grupos en ninguna de las dos dimensiones. Donde sí hubo diferencias es en la dimensión de valencia, mostrando que los consumidores de sustancias, en comparación con el grupo control, valoraban los estímulos de forma más extrema, puntuando las imágenes de sexo de forma más positiva y las aversivas de forma más negativa. Si bien todos los participantes, con independencia del grupo al que pertenecian, valoraban más las imágenes de sexo, en segundo lugar las de animales y por último, las negativas; al tiempo que percibian más control sobre las imágenes más valoradas (sexuales) que sobre los otros dos tipos de imágenes. En cuanto a las diferencias de sexo, no se encontraron ni en valencia ni en control, pero si en intensidad de la respuesta emocional, activándose más los hombres que las mujeres ante las imágenes sexuales, y las mujeres más que los hombres ante las aversivas o negativas.

La ausencia de diferencias entre drogodependientes y no consumidores en la dimensión de activación, o de intensidad de respuesta ante los estímulos visuales presentados, contradice resultados previos (Aguilar et al., 2008a y b), en los que los consumidores de sustancias se activaban significativamente menos que el grupo control ante imágenes agradables. Una posible explicación estaría en que el grupo de no consumidores del presente estudio era más similar en edad al grupo de adictos, y conociendo que la edad es una variable que influye en la experiencia emocional (Grühn y Scheibe, 2008), puede favorecer que los resultados difieran de los obtenidos en estudios previos.

En cuanto a la dimensión de dominancia se encontró que los estímulos aversivos provocaban una evaluación de menor control que los otros dos tipos de estímulos, pero de forma similar en los drogodependientes y en la población no consumidora. En estudios previos si se habian informado diferencias en pacientes ingresados, que mostraban más control ante los estímulos visuales que el correspondiente grupo de contraste no consumidor de sustancias (Aguilar et al., 2005a). Sería posible sugerir que la falta de diferencias en esta dimensión pueda estar relacionada con características metodológicas del presente estudio, como el distinto tipo de procedimiento seguido, la aplicación individual de la prueba, la utilización de pacientes ambulatorios, o la inclusión de un grupo control de similar edad.

Lo que si se ha encontrado en el presente estudio es una diferencia en la dimensión de valencia, mostrando los adictos, en comparación con el grupo control, una valoración más extrema de los estímulos visuales, valorando más positivamente las imágenes positivas o de sexo y más negativamente las aversivas.
Este resultado de valoración extrema fue informado por Grühn y Scheibe (2008) que compararon la respuesta emocional de dos grupos no consumidores diferenciados en edad. Estos autores encontraron que el grupo de mayores presentaba esta respuesta emocional extrema con respecto a los más jóvenes. En nuestro estudio, esta diferencia no podría ser explicada por esta variable, ya que ambos grupos tenian una edad equivalente. Puede ser que la afectación en las funciones ejecutivas en los drogodependientes, debida al consumo, y en las personas más mayores, debida a la edad (el grupo del estudio mencionado tenía una edad media de 70 años), podría producir una experiencia emocional similar.

Este mismo resultado se ha informado también cuando la muestra estaba formada por adictos a cocaina al compararse con un grupo de adictos a la heroína y otro con adicción a ambas sustancias (Aguilar et al., 2005b). En nuestro estudio, esta comparación en función de la sustancia no se pudo realizar, por el distinto número de personas, a veces muy poco representativo, adictas a cada sustancia. Sin embargo, si tenemos en cuenta que el grupo más numeroso del presente estudio, representando algo más del $42 \%$ de la muestra de adictos estaba formada por consumidores de cocaina, se apoyaría en parte el resultado anteriormente indicado.

En cuanto a las diferencias de sexo sí se confirmó la hipótesis planteada indicando que las mujeres se activarian más que los varones ante las imágenes aversivas (Lang et al., 1988; Lang, Bradley y Cuthbert, 1997; Moltó et al., 1999; Vila et al., 2001), con independencia del consumo o no de sustancias adictivas. Por otra parte, y aunque no se formuló inicialmente una hipótesis al respecto, se encontró que todas las mujeres se activaban menos que los hombres, con independencia del grupo al que pertenecieran, ante las imágenes sexuales. Estos resultados han sido informados previamente en la literatura cientifica, aunque han recibido bastantes críticas (ver Rupp y Wallen, 2008, para una revisión). La mayor intensidad en la respuesta de los hombres parece estar más directamente relacionada con el contenido del estímulo o imagen, mientras que en las mujeres esta reacción podría estar mediada o moderada no sólo por aspectos físicos como los niveles hormonales, sino también por los roles aprendidos y reforzados socialmente. En apoyo de esta idea, análisis más pormenorizados revelaron que la imagen sexual que recibía más activación y era valorada más positivamente por las mujeres era la menos explícita sexualmente. Ante este resultado se podría sugerir que no es que las mujeres se activen menos, sino que preferirian otros estímulos sexuales (Rupp y Wallen, 2008). En futuras investigaciones deberian incluirse un número equivalente de imágenes explícitas y no explícitas para poder corroborar esta sugerencia.

En este estudio podemos señalar algunas limitaciones, unas derivadas de la composición de la muestra y otras relacionadas con la medida de las emociones. En relación con la primera, se deberian tener en cuenta en el grupo de drogodependientes distintos aspectos relacionados con el consumo, como por ejemplo, el tipo de sustancia consumida, el tiempo de consumo, o el tiempo transcurrido desde el último consumo, variables que se han revelado importantes en el análisis de la experiencia emocional de personas adictas (Aguilar et 
al., 2005a, 2005b, 2008a, 2008b). En el presente estudio no pudimos analizar la influencia del tipo de sustancia por no disponer de muestra suficiente para ello. De la misma forma, tampoco pudimos incluir las variables relacionadas con el tiempo de consumo o con el tiempo transcurrido desde el último consumo, porque al tratarse de pacientes en régimen ambulatorio no había suficientes garantías sobre la objetividad de los informes recogidos. Sería importante en futuras investigaciones disponer de esta información, de la manera más fiable posible, con el fin de contrastar los resultados obtenidos en funcionamiento emocional con los encontrados en muestras hospitalizadas, donde dichos registros si se pueden obtener con las garantías necesarias.

Con respecto a la medida de las emociones utilizando el IAPS, se deberian emplear en futuros estudios diferentes tipos de imágenes dependiendo de qué se pretende analizar. Además de lo comentado anteriormente sobre las imágenes sexuales, sería conveniente emplear imágenes más relacionadas con el consumo de sustancias, lo que probablemente permitiría encontrar mayores diferencias entre el grupo de drogodependientes y la muestra no clínica. Por otra parte, parece que los diferentes procedimientos utilizados cuando se emplea el IAPS pueden estar influyendo en los resultados obtenidos. Un uso del IAPS más estandarizado podría subsanar estos errores y hacer los estudios más comparables. Podría ser útil, asimismo, complementar las imágenes del IAPS con otros escenarios donde las emociones que se eliciten sean más complejas (Damasio, 2003), ya que posiblemente las emociones que pueden mantener una conducta adictiva no son simples y no se producen ante la mera exposición a imágenes. Se deberian plantear estudios que, manteniendo la ética, presentasen a los sujetos un nivel de estrés mayor, determinado por una mayor demanda externa y un análisis de los recursos propios para hacer frente a la misma, lo que favorecería una mayor validez ecológica en las emociones generadas.

A pesar de estas limitaciones, en el presente estudio se encontraron diferencias significativas en la experiencia emocional entre adictos y no consumidores, diferencias que pueden influir en la toma de decisiones y que pueden estar relacionadas con el mantenimiento de la conducta adictiva, aspecto que debe seguir investigándose por su interés en el abordaje de las drogodependencias. Por su parte, la dimensión de dominancia o control, a pesar de no haber ofrecido en el presente estudio resultados relevantes en función del tipo de población analizada, podría representar lo que ocurre en el procesamiento emocional y en el control de impulsos, aspecto en el que debería profundizarse en futuros estudios.

Finalmente, habría que señalar que las terapias para las conductas adictivas se han centrado primordialmente en los aspectos cognitivos de las adicciones (prevención de recaídas, afrontamiento del estrés, etc.). Podría esperarse que terapias centradas en la emoción, pudieran ser una herramienta útil en el tratamiento de los drogodependientes. Para ello, el presente trabajo, los ya realizados y los siguientes que se hagan, sobre este tema, pueden aumentar el conocimiento que se tiene del proceso de la experiencia emocional. Entendiendo mejor el procesamiento de las emociones en consumidores de drogas, se pueden encontrar soluciones a problemas aún no resueltos en la clínica de las conductas adictivas. El presente trabajo ha intentado profundizar en este conocimiento y a su vez mejorar la metodología, resaltando la importancia de su unificación cuando se emplea el IAPS cómo método para estudiar la experiencia emocional.

\section{Conflicto de intereses}

Los autores del artículo manifiestan no tener ningún conflicto de intereses.

\section{Referencias}

American Psychiatric Association (2002). DSM-IV-TR. Manual diagnóstico y estadistico de los trastornos mentales. Barcelona: Masson.

Aguilar, F., Verdejo, A., Ceverino, A., Montanez, M., Lopez-Juarez, E., Sanchez-Barrera, M.,... PEPSA team (2008a). Dysregulation of emotional response in current and abstinent heroin users: negative heightening and positive blunting. Psychopharmacology 198, 159-166.

Aguilar, F., Verdejo, A., López-Jiménez, A., Montañez, M., GómezJuárez, E., Arráez, F. y Pérez-García, M. (2008b). Cambios en la respuesta emocional ante estímulos visuales de contenido sexual en adictos a las drogas. Adicciones, 20, 117- 124.

Aguilar, F., Verdejo, A., Peralta, M. I., Sánchez-Barrera, M. y PérezGarcia, M. (2005a). Experience of emotions in substance abusers exposed to images containing neutral, positive, and negative affective stimuli. Drug \& Alcohol Dependence, 78, 159-167.

Aguilar, F., Verdejo, A., Sánchez Barrera, M. B., López Jiménez, A. y Pérez-García, M. (2005b). Perfil emocional de los consumidores de "revuelto" en comparación con consumidores de heroína y de cocaina. Adicciones, 17, 131-138.

Damasio, A. R. (1994). Descartes' error: Emotion, reason and the human brain. NY: Grosset/Putnam.

Damasio, A. R. (2003). Looking for Spinoza: Joy, sorrow, and the feeling brain. NY: A Harvest Book/Harcourt.

Del Pozo, J. (2005). Retos y perspectivas sobre las drogodependencias y género. Salud y Drogas, 5, 117-135.

Gerra, G., Baldaro, B., Zaimovic, A., Moi, G., Bussandri, M., Raggi, M.A. y Bambrilla, F. (2003). Neuroendocrine responses to experimentallyinduced emotions among abstinent opioid-dependent subjects. Drug \&t Alcohol Dependence, 71, 25-35

Goldstein, R. Z. y Volkow, N. D. (2002). Drug addiction and its underlying neurobiological basis: Neuroimaging evidence for the involvement of the frontal cortex. American Journal of Psychiatry, 159, 1642-1652.

Grühn, D. y Scheibe, S. (2008). Age-related differences in valence and arousal ratings of pictures from the International Affective Picture System (IAPS): Do ratings become more extreme with age? Behavior Research Methods, 40, 512-521.

Lang, P. J. (1980). Behavioral treatment and bio-behavioral assessment: Computer applications. En J. B. Sodowski, J. H. Johnson y T. A. Williams (Eds.), Technology in mental care delivery systems (pp. 119-137). Norwood, NJ: Ablex. 
Lang, P.J. (1985). The cognitive psychophysiology of emotion: fear and anxiety. En A. H. Tuma y J. Mase (Eds.), Anxiety and the anxiety disorders. Hillsdale, NJ: Lawrence Erlbaum Associates.

Lang, P. J. (1994). The motivational organization of emotion: Affectreflex connections. En S. H. M. Van Goozen, N. Van de Poll y J. A. Sergeant (Eds.), Emotions: Essays on emotion theory (pp. 61-39). Hillsdale, NY: Lawrence Erlbaum Associates.

Lang, P. J. (1995). The emotion probe: Studies of motivation and attention. American Psychologist, 50, 372-385.

Lang, P. J., Bradley, M. M. y Cuthbert, B. N., (1997). Motivated attention: Affect, activation an action. En P. J. Lang, P. J. Simons y M. Balaban (Eds.), Attention and orienting: Sensory and motivational process (pp. 97-135). Hillsdale, NY: Lawrence Erlbaum Associates.

Lang, P. J., Bradley, M. M., y Cuthbert, B. N. (1999). International Affective Picture System (IAPS): Technical manual and affective ratings. Gainesville: The Center for Research in Psychophysiology, University of Florida.
Lang, P. J.; Öhman, A. y Vaitl, D., (1988). The International Affective Picture System (Photographic slides). Gainesville, FL: University of Florida, Center for Research in Psychophysiology.

LeDoux, J. (1996). The emotional brain: The mysterious underpinnings of emotional life. New York: Simon and Schuster.

Moltó, J., Montañes, S., Poy, R. y Segarra, P. (1999). Un nuevo método para el estudio de las emociones: El International Affective Picture System (IAPS) adaptación española. Revista de Psicología General y Aplicada, 52, 55-87.

Rupp, H.A., Wallen, K. (2008). Sex differences in response to visual sexual stimuli: A review. Archives of Sexual Behavior, 37, 206218.

Verdejo, A. y Bechara, A. (2009). A somatic marker theory of addiction. Neuropharmacology, 56, 48-62.

Vila, J., Sánchez, M. y Ramírez, I. (2001). El sistema internacional de imágenes afectivas (IAPS): Adaptación española. Segunda parte. Revista de Psicología General y Aplicada, 54, 635-657. 
